\title{
Commentary: Optimize preoperative glycemic control or carry on as usual?
}

\author{
Dustin Scott Kehler, MSc, PhD
}

\author{
From the Division of Geriatric Medicine, Dalhousie University, Halifax, Nova Scotia, Canada. \\ Disclosures: Author has nothing to disclose with regard to commercial support. \\ Received for publication Feb 12, 2019; accepted for publication Feb 12, 2019; available ahead of print April 5, \\ 2019. \\ Address for reprints: Dustin Scott Kehler, MSc, PhD, QEII Health Sciences Centre-Camp Hill Veterans Memorial \\ Building, Room 1314, 5955 Veterans' Memorial Lane, Halifax, Nova Scotia, B3H 2E1, Canada (E-mail: scott. \\ kehler@dal.ca). \\ J Thorac Cardiovasc Surg 2020;159:577-8 \\ $0022-5223 / \$ 36.00$ \\ Copyright (c) 2019 by The American Association for Thoracic Surgery \\ https://doi.org/10.1016/j.jtcvs.2019.02.060
}

Diabetes mellitus is a common problem in patients undergoing cardiac surgery. Both type 1 and type 2 diabetes are significantly associated with poor prognosis following surgical intervention. ${ }^{1}$ Maintaining optimal glycemic control is fundamental for all surgical patients regardless of diabetes status to improve their outcome, yet this goal is not always met. ${ }^{2}$ Surgery requiring cardiopulmonary bypass causes greater dysregulation in glycemic control, making off-pump procedures the preferred method for the patient with diabetes to improve their surgical outcome. ${ }^{3}$ Still, little is known regarding the impact of perioperative glycemic control and variability for patients with diabetes undergoing coronary artery bypass without the need for cardiopulmonary bypass.

In this issue of the Journal, Kim and colleagues ${ }^{4}$ determined whether perioperative glycemic control was associated with short-term morbidity and mortality among 703 patients with diabetes undergoing off-pump coronary artery bypass graft (CABG) surgery. Preoperatively, they separated patients into those having unstable glycemic control, defined as a hemoglobin A1c (HbA1c) level of $\geq 7 \%$ ( $\mathrm{n}=416 ; 59.2 \%)$, or stable glycemic control (HbA1c $<7 \% ; \mathrm{n}=287 ; 40.8 \%)$. Their investigation identified that $\mathrm{HbA} 1 \mathrm{c}$ levels of at least $7 \%$ independently increased the odds of the composite outcome of postoperative stroke, prolonged ventilation, deep sternal wound infection, renal failure, and 30-day mortality (odds ratio, 1.60; 95\% confidence interval, 1.03-2.50) independent of age, sex, comorbidities, and perioperative glycemic control. In contrast, glycemic variability before and shortly after CABG, measured as the coefficient of variation and by the time-weighted average glucose concentration, were not associated with short-term adverse outcomes. This finding contributes to the broader literature that preoperative glycemic control is associated with postoperative morbidity and mortality following $\mathrm{CABG}{ }^{5}$

Stable long-term glycemic control among patients with diabetes is needed to mitigate the risk of adverse

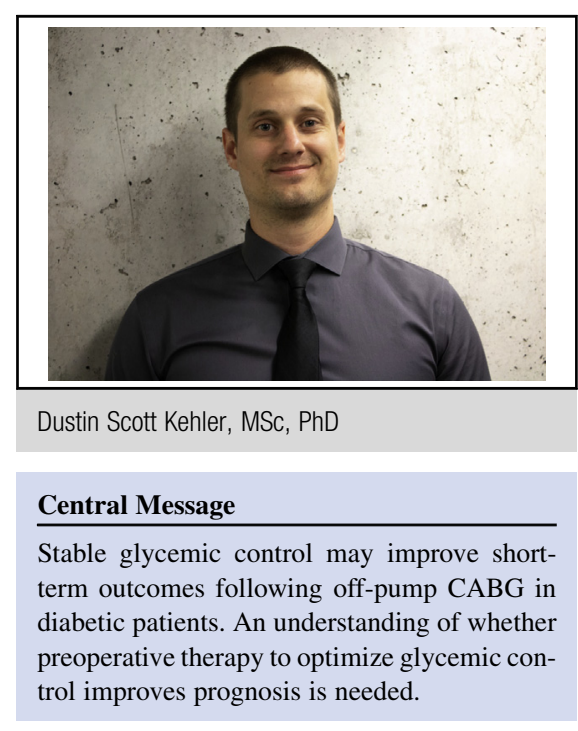

See Article page 568.

cardiovascular outcomes. ${ }^{6}$ Still, it is unclear what clinical benefit could be achieved from stabilizing glycemic control before off-pump CABG in patients with diabetes. In the investigation by Kim and colleagues, the odds of patients with diabetes experiencing an adverse outcome perioperatively was statistically significant, although somewhat low. ${ }^{4}$ Furthermore, the discriminative ability of HbAlc was as good as flipping a coin to predict short-term outcomes (area under the receiving operative curve: 0.55 for an $\mathrm{HbA} 1 \mathrm{c}$ of $7.85 \%$ ). We can then ask whether surgery should be delayed or carry on as usual despite poor management of glycemic control.

Alternatively, managing overall risk before CABG may be useful. Despite poor glycemic control over others, there were similarities in preoperative comorbid conditions. This may reflect other unmeasured issues, such as inadequate medical or behavioral management in some patients over others. Notably, greater presurgical physical activity levels may be associated with favorable short- and long-term prognosis, ${ }^{7,8}$ with preoperative exercise clinical trials showing significant benefits to hospital and patientoriented outcomes and a larger ongoing trial to determine its efficacy in frail older adults. ${ }^{9,10}$ Whether the manifold health benefits of physical activity extend to glycemic control before $\mathrm{CABG}$ for the provision of risk factor 
management would be informative, specifically for those placed on a surgical wait list.

\section{References}

1. Holzmann MJ, Rathsman B, Eliasson B, Kuhl J, Svensson AM, Nystrom T, et al Long-term prognosis in patients with type 1 and 2 diabetes mellitus after coronary artery bypass grafting. J Am Coll Cardiol. 2015;65:1644-52.

2. Halkos ME, Puskas JD, Lattouf OM, Kilgo P, Kerendi F, Song HK, et al Elevated preoperative hemoglobin Alc level is predictive of adverse events after coronary artery bypass surgery. J Thorac Cardiovasc Surg. 2008;136: 631-40.

3. Huang KC, Wu IH, Chou NK, Yang YY, Lin LC, Yu HY, et al. Late outcomes of off-pump versus on-pump coronary bypass in patients with diabetes: a nationwide study from Taiwan. J Thorac Cardiovasc Surg. 2019;157:960-9.e2.

4. Kim JH, Shim J, Youn Y, Song J, Lee H, Kwak Y. Influence of preoperative hemoglobin A1c on early outcomes in patients with diabetes mellitus undergoing off-pump coronary artery bypass surgery. J Thorac Cardiovasc Surg. 2020;159: 568-76.
5. Zheng J, Cheng J, Wang T, Zhang Q, Xiao X. Does HbAlc level have clinical implications in diabetic patients undergoing coronary artery bypass grafting? A systematic review and meta-analysis. Int J Endocrinol. 2017;2017: 1537213.

6. Gorst C, Kwok CS, Aslam S, Buchan I, Kontopantelis E, Myint PK, et al. Longterm glycemic variability and risk of adverse outcomes: a systematic review and meta-analysis. Diabetes Care. 2015;38:2354-69.

7. Kehler DS, Stammers AN, Tangri N, Hiebert B, Fransoo R, Schultz ASH, et al. Systematic review of preoperative physical activity and its impact on postcardiac surgical outcomes. BMJ Open. 2017;7:e015712.

8. Horne D, Kehler S, Kaoukis G, Hiebert B, Garcia E, Duhamel TA, et al. Depression before and after cardiac surgery: do all patients respond the same? J Thorac Cardiovasc Surg. 2013;145:1400-6.

9. Stammers AN, Kehler DS, Afilalo J, Avery LJ, Bagshaw SM, Grocott HP, et al. Protocol for the PREHAB study-pre-operative rehabilitation for reduction of hospitalization after coronary bypass and valvular surgery: a randomised controlled trial. BMJ Open. 2015;5:e07250.

10. Sawatzky JV, Kehler DS, Ready AE, Lerner N, Boreskie S, Lamont D, et al. Prehabilitation program for elective coronary artery bypass graft surgery patients: a pilot randomized controlled study. Clin Rehabil. 2014;28:648-57. 